\title{
Soliciting parental consent among adolescent minor mothers: A barrier in adolescent HIV research?
}

\begin{abstract}
Adolescents fare worse on the HIV prevention and treatment cascade than adults. ${ }^{[1,2]}$ This disparity may be particularly acute for adolescent minors (i.e. $<18$ years of age). ${ }^{[3]}$ Current trends show that adolescents, and especially adolescent minors, are a particularly vulnerable population with specific needs that are currently unmet.

The under-representation of adolescent minors (especially unemancipated individuals) in HIV research negatively affects the development and evaluation of interventions to improve their health. ${ }^{[4-6]}$ Despite growing consensus regarding the value of conducting HIV research with adolescent minors, ${ }^{[7-9]}$ concerns about perceived barriers to enrolling them persist. Specifically, researchers and adolescent minors in studies have voiced concerns that requiring parental consent might affect adolescent minors' autonomy and/or confidentiality. ${ }^{[5,10-15]}$ Despite these findings on adolescents' perceptions of parental consent, no quantitative studies have evaluated whether parental consent negatively affects adolescent minors' participation in HIV research. In addition, there are scant details describing the consent processes for enrolling adolescent minors into HIV studies. ${ }^{[5,16-18]}$ In this commentary, we describe strategies used to obtain parental consent for adolescent mothers to participate in an HIV prevention intervention and evaluate whether there were differences in enrolment rates of older adolescents compared with adolescent minors, who needed parental consent for study enrolment.
\end{abstract}

We conducted the Mentoring Adolescent Mothers in School (MAMAS) study, a pilot HIV prevention intervention to promote postpartum return to school among adolescent mothers (aged 14 19 years) in Umlazi, a township near Durban, South Africa (SA). Mothers were screened for eligibility at a public hospital maternity ward between July 2017 and April 2018.

Parental consent was sought for adolescent minors, with the minor's permission. In the absence of a parent, a court-appointed guardian could provide consent. Informed consent and/or assent were obtained at the research site (on the hospital grounds) or at home. All adolescents (and parents/guardians of minors) were required to sign consent/assent forms. MAMAS staff implemented three strategies to solicit parental consent. First, staff leveraged the fact that a parent/guardian had to be with the adolescent mother when she was discharged from the hospital. Specifically, staff approached the parent/guardian after discharge activities to describe the intervention, share study materials and solicit parental consent. Second, if the parent/guardian could not stay, staff offered to provide transport after discharge activities to explain the study on the ride home. Lastly, staff also provided flexible clinic hours for the parent/guardian to complete the informed consent process. To address concerns of confidentiality, adolescents (and parents/guardians of minors) were informed during the consent process that collected data would not be disclosed to their parents/guardians, with exceptions per SA laws. ${ }^{[19]}$

Of 464 screened adolescent mothers, 138 were eligible: 57 were adolescent minors (aged $14-17$ years) and 81 were older adolescents (aged 18 - 19). Of eligible participants, 87\% (120/138) enrolled in the study: 52 adolescent minors and 68 older adolescents. There was no statistical difference in enrolment rates between adolescent minors and older adolescents (91\% (95\% CI 81 - 97) v. 84\% (95\% CI 74 - 91), respectively; $p=0.31$ ).

Our finding that parental consent did not negatively affect enrolment is consistent with studies in other African contexts, wherein some adolescents did not perceive parental consent as a barrier to participation. ${ }^{[15,20,21]}$ Conversely, findings contradict other studies that have explored adolescents' perceptions on how parental consent might affect their participation in an HIV research study. Adolescent minors in these studies have mentioned the following perceived barriers to participation: parental access to sensitive health information, potential disapproval, and interpretation of their participation as being sexually active or LGBTQ. ${ }^{[10-12,15]}$

The findings and variation in perceptions of consent in existing literature serve as a reminder that adolescent minors comprise a heterogeneous population; soliciting parental consent may therefore differ based on contextual factors. It is possible that obtaining parental consent did not affect adolescent mothers' participation, because their parents were aware that they were sexually active, given that they had recently been pregnant. However, parental consent may be more difficult to obtain for other groups of adolescents (e.g. sexually active nulliparous or sexual minority), owing to fear of being ostracised by peers or reprimanded by their parents. ${ }^{[5]}$ Furthermore, parental consent may be more difficult to obtain in HIV research studies where the intervention outcome is not education, but is tied to more stigmatised outcomes (e.g. pre-exposure prophylaxis adherence, sexually transmitted infection incidence and/or HIV status). Future research should quantitatively examine differences in participation in intervention studies with explicit HIV-related outcomes among other groups of adolescents.

The implementation of appropriate and feasible recruitment and enrolment strategies may be beneficial to the enrolment of adolescent minors in HIV research studies. First, conducting formative research with the target population to determine and implement the most appropriate recruitment strategies ${ }^{[16]}$ could make adolescent minors more comfortable with parental involvement in the consent process. Second, involving other adolescents via social networks may enhance recruitment, ${ }^{[17]}$ while conducting community outreach will improve community buy-in and ensure that parents are on board. ${ }^{[18]}$ Lastly, differentiating between confidential and non-confidential data during the consent process will help adolescent minors understand the parameters of their rights to privacy. ${ }^{[18]}$

Parent-involved enrolment strategies may also maximise adolescent retention. Although involving the parent/guardian was not required for older adolescents ( $\geq 18$ years), MAMAS staff attempted to contact their parents/guardians to share study procedures (with the adolescent's consent). In-depth interviews with staff revealed that research assistants felt that older adolescents whose parents/ guardians were informed had better retention than those whose parents/guardians could not be reached. This is particularly relevant in countries other than SA which consider adolescent minor mothers to be emanicipated minors who therefore do not require parental consent for study participation. Involving parents/guardians by obtaining their consent and/or simply describing the intervention to them could be beneficial in the uptake of and retention in HIV research among all adolescents. This could also be examined quantitatively in future studies.

Our study suggests that soliciting parental consent was not a barrier to adolescent minor mother enrolment in HIV prevention research. Although parental involvement in HIV research may be a concern for some adolescent minors, implementing feasible and accessible enrolment and recruitment strategies may minimise 
barriers and maximise adolescent minors' positive health outcomes. Given the massive burden of the HIV epidemic on adolescent minors, and especially adolescent mothers, ${ }^{[22]}$ they should not be overlooked in HIV research.

\section{Luwam T Gebrekristos}

Department of Community Health and Prevention, Dornsife School of Public Health, Drexel University, Philadelphia, Penn., USA lg526@drexel.edu

\section{Zinhle Shazi, Dhayendre Moodley}

Department of Obstetrics and Gynaecology, Nelson R Mandela School of Medicine, University of KwaZulu-Natal, Durban, South Africa

\section{Suzanne Maman}

Department of Health Behavior, Gillings School of Global Public Health, University of North Carolina at Chapel Hill, NC, USA

\section{Allison K Groves}

Department of Community Health and Prevention, Dornsife School of Public Health, Drexel University, Philadelphia, Penn., USA

1. Joint United Nations Programme on HIV and AIDS (UNAIDS). Global HIV \& AIDS statistics - 2020 fact sheet. https://www.unaids.org/en/resources/fact-sheet (accessed 30 September 2020).

2. United Nations Children's Fund (UNICEF). Adolescent HIV prevention: Turning the tide against AIDS will require more concentrated focus on adolescents and young people. July 2020. https://data. unicef.org/topic/hivaids/adolescents-young-people/ 2018; (accessed 30 September 2020).

3. Naswa S, Marfatia YS. Adolescent HIV/AIDS: Issues and challenges. Indian J Sex Transm Dis AIDS 2010;31(1):1-10. https://doi.org/10.4103/2589-0557.68993

4. Borek N, Allison S, Cáceres CF. Involving vulnerable populations of youth in HIV prevention clinical research: J Acquir Immune Defic Syndr 2010;54:S43-S49. https://doi.org/10.1097/ qai.0b013e3181e3627d

5. DiClemente RJ, Sales JM, Borek N. Barriers to adolescents' participation in HIV biomedical prevention research J Acquir Immune Defic Syndr 2010;54(Suppl 1):S12-S17. https://doi.org/10.1097/ qai.0b013e3181ele2c0

6. Nelson RM, Lewis LL, Struble K, Wood SF. Ethical and regulatory considerations for the inclusion of adolescents in HIV biomedical prevention research. J Acquir Immune Defic Syndr 2010;54:S18-S24. https://doi.org/10.1097/qai.ob013e3181e2012e
7. Katusiime C, Parkes-Ratanshi R, Kambugu A. Transitioning behaviourally infected HIV-positive young people into adult care: Experiences from the young person's point of view. South Afr J HIV Med 2013:14(1):20-24. https://doi.org/10.4102/sajhivmed.v14i1.98

8. Lall P, Lim SH, Khairuddin N, Kamarulzaman A. An urgent need for research on factors impacting adherence to and retention in care among HIV-positive youth and adolescents from key populations. J Int AIDS Soc 2015;18:19393. https://doi.org/10.7448/ias.18.2.19393

9. Phillips SJ, Mbizvo MT. Empowering adolescent girls in sub-Saharan Africa to prevent unintended pregnancy and HIV: A critical research gap. Int J Gynaecol Obstet 2016;132(1):1-3. https://doi. org/10.1016/j.ijgo.2015.10.005

10. Fisher CB, Arbeit MR, Dumont MS, Macapagal K, Mustanski B. Self-consent for HIV prevention research involving sexual and gender minority youth: Reducing barriers through evidence-based ethics. J Empir Res Hum Res Ethics 2016;11(1):3-14. https://doi.org/10.1177/1556264616633963

11. Flicker S, Guta A. Ethical approaches to adolescent participation in sexual health research. J Adolesc Flicker S, Guta A. Ethical approaches to adolescent participation in sexu
Health 2008;42(1):3-10. https://doi.org/10.1016/j.jadohealth.2007.07.017

12. Jaspan HB, Soka NF, Mathews $\mathrm{C}$, et al. A qualitative assessment of perspectives on the inclusion of adolescents in HIV vaccine trials in South Africa. Int J STD AIDS 2010;21(3):172-176. https://doi. org/10.1258/ijsa.2009.008484

13. Lesch E, Kruger L-M. Mothers, daughters and sexual agency in one low-income South African community. Soc Sci Med 2005;61(5):1072-1082. https://doi.org/10.1016/j.socscimed.2005.01.005

14. Zuch M, Mason-Jones AJ, Mathews C, Henley L. Changes to the law on consent in South Africa: Implications for school-based adolescent sexual and reproductive health research. BMC Int Health Hum Rights 2012;12(1):1-5. https://doi.org/10.1186/1472-698x-12-3

15. Shah SK, Essack Z Byron $K$, et al. Adolescent barriers to HIV prevention research: Are parental consent requirements the biggest obstacle? J Adolesc Health 2020;67(4):495-501. https://doi. org/10.1016/j.jadohealth.2020.05.011

16. Fortune T, Wright E, Juzang I, Bull S. Recruitment, enrollment and retention of young black men for HIV prevention research: Experiences from the 411 for Safe Text project. Contemp Clin Trials 2010;31(2):151-156. https://doi.org/10.1016/j.cct.2009.12.004

17. Valente TW, Zogg JB, Christensen S, Richardson J, Kovacs A, Operskalski E. Using social networks to recruit an HIV vaccine preparedness cohort. J Acquir Immune Defic Syndr 2009;52(4):514-523. https://doi.org/10.1097/qai.0b013e3181acff9l

18. Wallace M, Middelkoop K, Smith P, et al. Feasibility and acceptability of conducting HIV vaccine trials in adolescents in South Africa: Going beyond willingness to participate towards implementation. S Afr in adolescents in South Africa: Going beyond willingness to participate towards

19. South African Government. Criminal Law (Sexual Offences and Related Matters) Amendment Act 32 of 2007. https://www.gov.za/documents/criminal-law-sexual-offences-and-related-mattersamendment-act\# (accessed 14 August 2019)

20. Groves AK, Hallfors DD, Iritani BJ, et al. 'I think the parent should be there because no one was born alone': Kenyan adolescents' perspectives on parental involvement in HIV research. Afr J AIDS Res 2018;17(3):227-239. https://doi.org/10.2989/16085906.2018.1504805

21. Jaspan HB, Berwick JR, Myer L, et al. Adolescent HIV prevalence, sexual risk, and willingness to participate in HIV vaccine trials. J Adolesc Health 2006;39(5):642-648. https://doi.org/10.1016/j. jadohealth.2006.05.016

22. Groves AK, Maman S, Stankard PH, Gebrekristos LT, Amon JJ, Moodley D. Addressing the unique needs of adolescent mothers in the fight against HIV. J Int AIDS Soc 2018;21(6):e25155. https://doi, org/10.1002/jia2.25155

S Afr Med J 2021;111(6):526-527. https://doi.org/10.7196/SAMJ.2021.v111i6.15364 